\title{
454-Pyrosequencing Analysis of Bacterial Communities from Autotrophic Nitrogen Removal Bioreactors Utilizing Universal Primers: Effect of Annealing Temperature
}

\author{
Alejandro Gonzalez-Martinez, ${ }^{1}$ Alejandro Rodriguez-Sanchez, ${ }^{2}$ \\ Belén Rodelas, ${ }^{2}$ Ben A. Abbas, ${ }^{3}$ Maria Victoria Martinez-Toledo, ${ }^{2}$ \\ Mark C. M. van Loosdrecht, ${ }^{3}$ F. Osorio, ${ }^{1}$ and Jesus Gonzalez-Lopez ${ }^{2}$ \\ ${ }^{1}$ Department of Civil Engineering, University of Granada, Campus de Fuentenueva, s/n, 18071 Granada, Spain \\ ${ }^{2}$ Institute of Water Research, University of Granada, C/Ramón y Cajal 4, 18071 Granada, Spain \\ ${ }^{3}$ Department of Biotechnology, Technical University of Delft, Julianalaan 67, 2628 BC Delft, Netherlands
}

Correspondence should be addressed to Alejandro Gonzalez-Martinez; agon@ugr.es

Received 20 October 2014; Accepted 26 February 2015

Academic Editor: Weixing Feng

Copyright (c) 2015 Alejandro Gonzalez-Martinez et al. This is an open access article distributed under the Creative Commons Attribution License, which permits unrestricted use, distribution, and reproduction in any medium, provided the original work is properly cited.

\begin{abstract}
Identification of anaerobic ammonium oxidizing (anammox) bacteria by molecular tools aimed at the evaluation of bacterial diversity in autotrophic nitrogen removal systems is limited by the difficulty to design universal primers for the Bacteria domain able to amplify the anammox 16S rRNA genes. A metagenomic analysis (pyrosequencing) of total bacterial diversity including anammox population in five autotrophic nitrogen removal technologies, two bench-scale models (MBR and Low Temperature CANON) and three full-scale bioreactors (anammox, CANON, and DEMON), was successfully carried out by optimization of primer selection and PCR conditions (annealing temperature). The universal primer $530 \mathrm{~F}$ was identified as the best candidate for total bacteria and anammox bacteria diversity coverage. Salt-adjusted optimum annealing temperature of primer $530 \mathrm{~F}$ was calculated $\left(47^{\circ} \mathrm{C}\right)$ and hence a range of annealing temperatures of $44-49^{\circ} \mathrm{C}$ was tested. Pyrosequencing data showed that annealing temperature of $45^{\circ} \mathrm{C}$ yielded the best results in terms of species richness and diversity for all bioreactors analyzed.
\end{abstract}

\section{Introduction}

Anaerobic ammonium oxidizing (anammox) bacteria belong to the Candidatus Brocadiales order first described in 1999 [1]. Their ability to perform anaerobic ammonium oxidation has attracted the attention of many researchers due to the change it made for the understanding of the nitrogen cycle. They have been found as important bacteria for the ecology of nitrogen in oceanic environments [2-4] and have been proposed to play an important role in the nitrogen cycle at global scale [2]. Anammox bacteria have been identified in many natural and engineered environments such as marine sediments, agricultural soils, or wastewater treatment plants [5-7]. In addition, anammox bacteria are the basis for promising technologies aimed at removing nitrogen from wastewater.
The autotrophic, anaerobic ammonium oxidation has been utilized for the set-up of several technologies for nitrogen removal, such as partial nitritation/anammox, DEMON, OLAND, or CANON [8]. Autotrophic nitrogen removal technologies account for several advantages over traditional total nitrification-denitrification processes, such as the lesser bioreactor volume required, lower biomass production, or saving costs in aeration and carbon source requirements [911]. Thus, anammox bacteria have become of relevance in both natural and engineered systems, and more research about the ecology of the ecosystems where they develop is expected in the following years.

PCR-based molecular biology techniques such as qPCR quantification and high-throughput pyrosequencing are powerful tools for the estimation of the abundance 
and diversity of microorganisms in natural and engineered ecosystems [12, 13]. Most frequently, anammox-specific primers have been applied for PCR-based evaluation of the occurrence and diversity of these organisms [12, 14-18]. The reason under this common practice is that universal primers targeting the whole Bacteria domain tend to amplify poorly the $16 \mathrm{~S}$ rRNA gene of anammox due to their not very high identity $(<87.1 \%)[19,20]$. In this sense, when universal primers are used PCR amplification of some anammox phylotypes might be missing, with the consequent loss of fundamental information on the microbial diversity of the system. Nevertheless, the use of anammox-specific primers is not sufficient for a complete understanding of microbial ecosystems, given that other bacteria are not taken into account.

In this research, several universal primers and annealing temperature conditions for PCR amplification were tested in order to achieve the best combination possible for its use on the metagenomic analysis of ecosystems, such as autotrophic nitrogen removal bioreactors. After an in silico testing, a universal primer was selected for the best coverage of $16 \mathrm{~S}$ rRNA genes of the domain Bacteria including anammox (Planctomycetes). Using this primer, bacterial diversity in samples from five different lab-scale and full-scale autotrophic nitrogen removal bioreactors (see Table S1 in Supplementary Materials available online at http://dx.doi.org/10.1155/2015/892013) were analyzed by highthroughput pyrosequencing, using six different annealing temperatures. Based on the results obtained, a robust method for the evaluation of the bacterial diversity in ecosystems where anammox bacteria are of importance is proposed.

\section{Materials and Methods}

2.1. Bioreactors. Five different autotrophic nitrogen removal bioreactors which represent the main existing anammox technologies were sampled in the analysis (Table S1). Two of them were bench-scale models and the other three were full-scale plant bioreactors. The bench-scale models analyzed in the study were named Lab MBR and Low Temperature CANON. Lab MBR is a membrane bioreactor (MBR) anammox system and Low Temperature CANON is a CANON system operated at $15^{\circ} \mathrm{C}$. Both bioreactors were built in Netherlands in 2010 and 2009, respectively, and were fed synthetic wastewater.

The full-scale bioreactors sampled in the study were located at three cities in Netherlands, Apeldoorn, Olburgen, and Rotterdam, and were named $\mathrm{A}, \mathrm{N}$, and $\mathrm{R}$, respectively. Bioreactor A is a DEMON system built in 2010 which treats reject water from anaerobic digester. Bioreactor $\mathrm{N}$ is a CANON process treating sewage from a potato processing factory built in 2009. Bioreactor $\mathrm{R}$ is the anammox reactor in a two-step anammox plant constructed in 2002 and treats reject water from anaerobic digester.

2.2. Sampling. Five samples $(200 \mathrm{~mL})$ were taken from five evenly distributed points within each bioreactor volume. The procedures for sampling and pretreatment for DNA extraction followed those described by $\mathrm{Ni}$ et al. [16]. Biomass was separated from the collected wastewater by centrifugation at $3500 \mathrm{rpm}$ for 10 minutes at room temperature in a Kokusan H-103N series apparatus (Kokusan Enshinki Co., Ltd., Tokyo, Japan). Pelleted biomass was stored at $-20^{\circ} \mathrm{C}$ before DNA extraction.

2.3. In Silico Primer Evaluation. The primer pair $530 \mathrm{~F}$ (5'-GTGCCAGCMGCNGCGG)-1100R (5'-GGGTTNCGNTCGTTG), described by Dowd et al. [21], was selected after an in silico analysis of several universal primers targeting the 16S rRNA gene and commonly used in earlier literature. The primers were tested by correlating the accession numbers of the matching sequences, using the Probe Match function of the Ribosomal Data Project (RDP) (http://rdp.cme.msu.edu/probematch/search.jsp) (see Supplementary Material). Moreover, to double check the performance of the selected primer set over the Planctomycetes phylum, an extra in silico analysis study using the SiLVA Test Probe tool was done (http://www.arb-silva.de/search/ testprobe).

2.4. In Silico Calculation of Optimum Annealing Temperature. Calculation of optimum annealing temperature for primer $530 \mathrm{~F}$ was done following the expression for the optimum salt-adjusted annealing temperature of a primer developed by Rychlik et al. [22-25]. For calculation purposes, combined concentration of $\mathrm{Na}^{+}$and $\mathrm{K}^{+}$was taken as $50 \mathrm{mM}$.

2.5. DNA Extraction, PCR Amplification, and Pyrosequencing. $300 \mathrm{mg}$ of pelleted biomass for each centrifuged sample was used for DNA extraction using the Fast DNA SPIN Kit for Soil and the Fast-Prep24 apparatus (MP Biomedicals, Solon, OH, USA) following the instructions given by the manufacturer. DNA extracts from samples collected in the same bioreactor were merged into a pool. The DNA pool of each bioreactor was divided into 6 subsamples with equal volume for further pyrosequencing analysis.

The primer pair 530F-1100R [21] was used to amplify $500 \mathrm{bp}$ of the $16 \mathrm{~S}$ rRNA gene of Bacteria, encompassing the V4-V5-V6 hypervariable regions. Research and Testing Laboratory (Lubbock, Texas, USA) proceeded with pyrosequencing following the procedure described by Dowd et al., 2008 [21], using the Roche 454 GS-FLX+ apparatus. Amplification of the six subsamples within the same bioreactor DNA pool was assayed under the same PCR conditions but at different annealing temperatures ( 44 to $49^{\circ} \mathrm{C}$ ), yielding a total of 30 different pyrosequencing datasets in the five different technologies. In this sense the PCR conditions for pyrosequencing were the following: preheating step at $94^{\circ} \mathrm{C}$ for 3 minutes; 32 cycles at $94^{\circ} \mathrm{C}$ for 30 seconds, $44-49^{\circ} \mathrm{C}$ for 40 seconds, and $72^{\circ} \mathrm{C}$ for 1 minute; elongation at $72^{\circ} \mathrm{C}$ for 5 minutes.

2.6. Pyrosequencing Postrun Analysis. Elimination of poorquality end reads from pyrosequencing raw data was done by quality trimming based on quality scores. USEARCH [26] was then used to generate seed sequences to which 
quality trimmed reads were clustered within a $4 \%$ divergence threshold. This procedure eliminates sequences that fail to encounter similar enough reads. Chimera detection was developed using the de novo method implemented in UCHIIME [27] over clustered quality trimmed sequences collected during the previous step. Denoising was then conducted for elimination of bad sequences and correction of base pair errors. Following denoising, a quality control screening was conducted. Quality criteria taken were the following: (1) failed sequence reads, (2) sequences with low quality tags, and (3) sequences that are shorter than half the expected amplicon length or $250 \mathrm{bp}$, whichever the shortest. Sequences that could not meet the defined quality criteria were eliminated. Reads that passed the quality screening control were then clustered for phylogenetic identification into $0 \%$ divergence using USEARCH [26]. The Kraken BLAST software (http://ccb.jhu.edu/software/kraken/) [28] was utilized to provide a seed sequence for each phylogenetic identification cluster from a high-quality database derived from the NCBI GenBank database. Based on BLASTN+ identity, sequences were affiliated to distinct taxonomic levels as follows: (1) at OTU level if divergence was less than 3\%, (2) at genus level if divergence was in the range $3-5 \%$, (3) at family level if divergence was $5-10 \%,(4)$ at order level if divergence was $10-15 \%,(5)$ at class level if divergence was $15-20 \%$, and (6) at phylum level if divergence was $20-23 \%$. Sequences that did not encounter queried sequences with less than $23 \%$ divergence were discarded.

2.7. Rarefaction Curves. Rarefaction curves for each sample were calculated using the aRarefactWin software developed by S. Holland (University of Georgia, Athens; http:// strata.uga.edu/software/). For the purpose of microbial community analysis, rarefaction curves of samples belonging to the same bioreactor were interpolated to the lowest reads count among all of them and extrapolated to the highest reads count among all of them. Extrapolation of rarefaction curves was done following the mathematical model described in Colwell et al. [29].

2.8. Heat Maps. For each bioreactor, a heat map was generated defining the differences of community structure on the basis of the annealing temperatures selected for PCR. The heat maps were based on the relative abundance of OTUs > $1 \%$ relative abundance.

2.9. Cluster Analysis (CA). Three different types of cluster analysis (CA) were performed over the samples: "analysis $\mathrm{A}^{\text {" }}$ including all OTUs and using a non-phylogeny-dependent method; "analysis B" including only OTUs with $>1 \%$ relative abundance and using a non-phylogeny-dependent method; and "analysis C" including only OTUs with $>1 \%$ relative abundance and using a phylogeny-dependent method. Nonphylogeny-dependent $\mathrm{A}$ and $\mathrm{B}$ analysis were based on Bray-Curtis dissimilarity and carried out with the Vegan package v.2.0 implemented on the statistical software RProject v.2.15.1 [30]. The software Fast UniFrac [31] was utilized for the phylogeny-dependent $\mathrm{C}$ analysis, following instructions given by the developers in the software tutorial (http://unifrac.colorado.edu/). For this purpose, reference trees were constructed for each bioreactor, using the MEGA 6.0 software [32]. Relative abundances of each of the OTUs were used as weight for the analysis.

2.10. Principal Coordinates Analysis (PCoA). Principal coordinates analysis (PCoA) of samples coming from the same bioreactor was done based on a phylogeny-dependent method. OTUs with relative abundance $>1 \%$ were selected for the study. For each bioreactor, a reference tree with selected OTUs was constructed using MEGA 6.0 software. Utilizing reference trees, phylogeny-based PCoA was conducted using Fast UniFrac software [31], following the instructions given in the software tutorial (http://unifrac.colorado.edu/).

2.11. Hill Diversity Indices. Hill diversity indices of order 1 (Shannon index) and order 2 (Simpson index) were calculated for each sample using the Vegan package v.2.0 implemented on the statistical software R-Project v.2.15.1 [30].

\section{Results and Discussion}

3.1. In Silico Primer Evaluation. The design of a primer that covers all species within the domain Bacteria is impossible [33]. Therefore, when a primer is chosen for a bacterial community analysis, one has to accept that no total coverage could be found. For this reason, potential coverage of a primer is of primary importance in order to decide the best option for the analysis of microbial ecology of a natural ecosystem. Results of the in silico search for coverage of bacterial species of nine widely used universal primers within the RDP database are displayed in Table 1. Only results for the phylum Planctomycetes and the complete Bacteria domain are shown. Results for all other phyla can be seen in Table $\mathrm{S} 2$. The results of the in silico analysis showed that primer $530 \mathrm{~F}$ offered the best coverage of species for both the Bacteria domain and the phylum Planctomycetes. Primer 530F was able to discern $76.01 \%$ of the total bacterial species known to date. The closest follower was primer 519R, with $8 \%$ less total coverage. With regard to Planctomycetes, primer 530F covered $75.58 \%$ of species belonging to this group, while the second best (910R) covered 53.70\%.

Coverage of all phylotypes of anammox bacteria has been reported as very difficult if a universal primer is utilized $[19,20]$. In silico analysis of the coverage of all Candidatus Brocadiales microorganisms by primer $530 \mathrm{~F}$ within the SiLVA database is summarized in Table S3. We found that primer 530F targeted the $16 \mathrm{~S}$ rRNA genes of all the anammox Candidatus species known to date yielding a minimum of $90 \%$ perfect matches to sequences filed in the database. Thus, it can be stated that primer $530 \mathrm{~F}$ is the best option for the metagenomic analysis of autotrophic nitrogen removal bioreactors.

For the purposes of pyrosequencing, reverse primer $1100 \mathrm{R}$ was taken, following the literature that has utilized primer 530F for pyrosequencing analysis [21]. 
TABLE 1: In silico evaluation of primer coverage of species in the Bacteria domain and Planctomycetes specific.

\begin{tabular}{lcccccccc}
\hline Phylum & $27 \mathrm{~F}$ & $519 \mathrm{R}$ & $530 \mathrm{~F}$ & $787 \mathrm{R}$ & $910 \mathrm{R}$ & $1064 \mathrm{R}$ & $1392 \mathrm{R}$ & $1492 \mathrm{R}$ \\
\hline Planctomycetes & $17.82 \%$ & $23.89 \%$ & $75.58 \%$ & $6.17 \%$ & $53.70 \%$ & $39.88 \%$ & $33.25 \%$ & $6.59 \%$ \\
\hline Total & $\mathbf{1 1 . 5 8 \%}$ & $\mathbf{6 8 . 4 7 \%}$ & $\mathbf{7 6 . 0 1 \%}$ & $\mathbf{5 9 . 4 5 \%}$ & $\mathbf{5 6 . 5 3 \%}$ & $\mathbf{5 4 . 5 2 \%}$ & $\mathbf{2 2 . 0 8 \%}$ & $\mathbf{4 . 0 8 \%}$ \\
\hline
\end{tabular}

3.2. In Silico Optimum Annealing Temperature Calculation. Following the expression given by Rychlik et al. [22] for the salt-adjusted optimum melting temperature of primer $530 \mathrm{~F}$ with combined $\mathrm{N}^{+}$and $\mathrm{K}^{+}$concentration of $50 \mathrm{mM}$, as utilized by other authors [23-25], optimum melting temperature for primer $530 \mathrm{~F}$ was $47^{\circ} \mathrm{C}$. For the testing of different annealing temperatures an interval around optimum annealing temperature calculated was covered, ranging from $44^{\circ} \mathrm{C}$ to $49^{\circ} \mathrm{C}$.

3.3. Rarefaction Curves. For each bioreactor, original rarefaction curves, interpolated ones to lowest number of reads within samples, and extrapolated ones to the highest number of reads within samples were generated and are shown in Figure S1. It can be seen that annealing temperatures of $44^{\circ} \mathrm{C}$ offer lower species richness than all the other annealing temperatures tested.

3.4. Diversity and Relative Abundance of Bacterial Species. Heat maps were generated for each bioreactor taking into account only the OTUs with $>0.1 \%$ relative abundance as shown in Figures 1 and 2. Annealing temperature of $44^{\circ} \mathrm{C}$ showed a pattern that differed from those generated at all other temperatures in all bioreactors. Interestingly, at $44^{\circ} \mathrm{C}$ bacteria belonging to the Candidatus Brocadiales order (Candidatus Brocadia anammoxidans, Brocadia fulgida, and Brocadia sp.) showed a much lower relative abundance than that at all the other annealing temperatures tested for every bioreactor. Particularly, for the Lab MBR bioreactor, which stands as a highly enriched (>90\%) [34] culture of Brocadiales, the relative abundance found was $1.27 \%$ when $44^{\circ} \mathrm{C}$ was the annealing temperature, while at the other temperatures assayed it fell in the $75-86 \%$ range.

Amplification of partial $16 \mathrm{~S}$ rRNA genes of bacteria other than anammox was also influenced by the annealing temperature selected. In the case of the Lab MBR, the relative abundance of copies of Carboxydibrachium sp.was of $84.5 \%$ at $44^{\circ} \mathrm{C}$, much higher compared to the other annealing temperatures tested. The inability to capture any Candidatus Brocadiales phylotypes in all bioreactors, with one of those being a high enrichment of these bacteria, when annealing was performed at $44^{\circ} \mathrm{C}$ is related to a consistent error occurring during the PCR procedure of primer $530 \mathrm{~F}$. In this sense, it is possible that annealing at $44^{\circ} \mathrm{C}$ hinds the relative abundance of Candidatus Brocadiales bacteria under other bacterial species such as Carboxydibrachium sp. in the different pyrosequencing samples from the five bioreactors analyzed.

The results described here demonstrated that an annealing temperature of $44^{\circ} \mathrm{C}$ was inappropriate to analyze the bacterial community structure of the bioreactors sampled in the study, due to a severe underestimation of the relative abundance of Brocadiales.

Results of bacterial diversity obtained for bioreactors Lab MBR and Low Temperature CANON were further analyzed to check the performance of primer $530 \mathrm{~F}$ for the evaluation of anammox diversity. Diversity of anammox bacteria in bioreactors Lab MBR and Low Temperature CANON was studied before by other authors utilizing different molecular biology techniques, such as FISH or qPCR $[35,36]$. In these studies, it was concluded that Candidatus Brocadia fulgida was the only anammox bacteria in both Lab MBR and Low Temperature CANON bioreactors. In the present study, Candidatus Brocadia sp. was the only anammox identified in Lab MBR bioreactor, while in the Low Temperature CANON bioreactor, pyrosequencing with primer $530 \mathrm{~F}$ retrieved partial $16 \mathrm{~S}$ rRNA genes affiliated to four different anammox phylotypes: Candidatus Brocadia anammoxidans, Candidatus Brocadia fulgida, Candidatus Brocadia sp., and Candidatus Jettenia asiatica, all of them represented in low relative abundance with the exception of Candidatus Brocadia sp. Sequences for the OTUs identified as Candidatus Brocadia sp. in both Lab MBR and Low Temperature CANON bioreactors (305 and 289 nucleotides, resp.) shared 99\% similarity in 100\% query cover with four Candidatus Brocadia fulgida sequences found in the BLASTN database (JQ864319.1, JQ864321.1, JQ864322.1, Zheng \& Zhang, unpublished, and JX243455.1 [36]). Thus, it can be said that universal primer 530F can express in a consistent way the diversity of anammox bacteria found in autotrophic nitrogen removal bioreactors.

Failure to find Candidatus Brocadiales sequences at annealing temperature of $44^{\circ} \mathrm{C}$ can be related to a bias of PCR procedure. The relative abundance of Brocadia sp. and Carboxydibrachium sp. along with their ratio for the bioreactor Lab MBR can be seen in Table 2. The Carboxydibrachium sp./Brocadia sp. ratio abruptly increases when dropping from $45^{\circ} \mathrm{C}$ to $44^{\circ} \mathrm{C}$, while it stabilizes at temperatures of $45^{\circ} \mathrm{C}$ and higher. In accordance with our results, some studies have found that a small percentage of OTUs in chicken caecal samples suffered from distortions in relative abundance as their bacterial community structure was studied through RTPCR at different annealing temperatures, even though the entire microbial community structures were not subjected to major changes [37]. Also, changes in amplification of Vibrio vulnificus by RT-PCR at different annealing temperatures have been found [38]. Mismatches of primers with the targeted region of the DNA templates are thought to be the cause of differences in the estimation of the relative abundance of bacterial species in environmental samples. A higher number of mismatches in the targeted region lead to a higher bias of the relative abundance of certain OTUs. Among other factors, the annealing temperature is thought to cause mismatch of primers during PCR processes [33]. In this 


\begin{tabular}{|c|c|c|c|c|c|c|}
\hline \multirow{2}{*}{\multicolumn{7}{|c|}{\begin{tabular}{|c} 
Lab MBR \\
Acidobacterium sp.
\end{tabular}}} \\
\hline & & & & & & \\
\hline \multicolumn{7}{|l|}{ Alkalibacterium sp. } \\
\hline \multicolumn{7}{|l|}{ Brocadia sp. } \\
\hline \multicolumn{7}{|l|}{ Brumimicrobium sp. } \\
\hline \multicolumn{7}{|l|}{ Carboxydibrachium sp. } \\
\hline \multicolumn{7}{|l|}{ Chitinophaga sp. } \\
\hline \multicolumn{7}{|l|}{ Clostridium sp. } \\
\hline \multicolumn{7}{|l|}{ Flavobacterium sp. } \\
\hline \multicolumn{7}{|l|}{ Flexibacter sp. } \\
\hline \multicolumn{7}{|l|}{ Ignavibacterium album } \\
\hline \multicolumn{7}{|l|}{ Malonomonas sp. } \\
\hline \multicolumn{7}{|l|}{ Prochlorococcus sp. } \\
\hline \multicolumn{7}{|l|}{ Pseudoalteromonas $\mathrm{sp}}$. \\
\hline \multicolumn{7}{|l|}{ Sphingobacterium sp. } \\
\hline Thermoanaerobacter sp. & & & & & & \\
\hline
\end{tabular}

\begin{tabular}{|c|l|}
\hline$>1 \%$ & \\
\hline $2.50 \%$ & \\
\hline $5 \%$ & \\
\hline $7.50 \%$ & \\
\hline $10 \%$ & \\
\hline $15 \%$ & \\
\hline $25 \%$ & \\
\hline $50 \%$ & \\
\hline $75 \%$ & \\
\hline $100 \%$ & \\
\hline
\end{tabular}

\begin{tabular}{|c|c|c|c|c|c|c|}
\hline $\begin{array}{c}\text { Low Temperature } \\
\text { CANON }\end{array}$ & $44^{\circ} \mathrm{C}$ & $45^{\circ} \mathrm{C}$ & $46^{\circ} \mathrm{C}$ & $47^{\circ} \mathrm{C}$ & $48^{\circ} \mathrm{C}$ & $49^{\circ} \mathrm{C}$ \\
\hline \multicolumn{7}{|l|}{ Brocadia sp. } \\
\hline \multicolumn{7}{|l|}{ Carboxydibrachium sp. } \\
\hline \multicolumn{7}{|l|}{ Chloroflexus sp. } \\
\hline \multicolumn{7}{|l|}{ Clostridium sp. } \\
\hline \multicolumn{7}{|l|}{ Crocinitomix sp. } \\
\hline \multicolumn{7}{|l|}{ Cytophaga sp.. } \\
\hline \multicolumn{7}{|l|}{ Dokdonella sp } \\
\hline \multicolumn{7}{|l|}{ Flavobacterium sp. } \\
\hline \multicolumn{7}{|l|}{ Fluviicola sp } \\
\hline \multicolumn{7}{|l|}{ Nitrosomonas halophila } \\
\hline \multicolumn{7}{|l|}{ Nitrosomonas sp. } \\
\hline \multicolumn{7}{|l|}{ Pseudoxanthomonas sp. } \\
\hline \\
\hline \multicolumn{7}{|l|}{ Rhodoglobus sp. } \\
\hline Undibacterium sp. & & & & & & \\
\hline
\end{tabular}

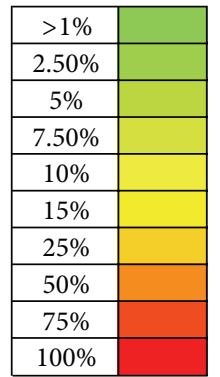

FIGURE 1: Heat maps of OTUs $>1 \%$ relative abundance in lab-scale bioreactors LAB MBR and Low Temperature CANON.

TABLE 2: Relative abundances of Brocadia sp., Carboxydibrachium sp. and the ratio of relative abundances Carboxydibrachium sp. to Brocadia sp. for the Lab MBR reactor.

\begin{tabular}{|c|c|c|c|c|c|c|}
\hline \multicolumn{7}{|c|}{ Lab MBR } \\
\hline & $44^{\circ} \mathrm{C}$ & $45^{\circ} \mathrm{C}$ & $46^{\circ} \mathrm{C}$ & $47^{\circ} \mathrm{C}$ & $48^{\circ} \mathrm{C}$ & $49^{\circ} \mathrm{C}$ \\
\hline \multicolumn{7}{|l|}{ Species } \\
\hline Brocadia sp. (\%) & 1.04 & 75.15 & 86.76 & 79.51 & 77.68 & 75.77 \\
\hline Carboxydibrachium sp. (\%) & 84.50 & 0.81 & 0.77 & 0.44 & 0.26 & 0.13 \\
\hline C. sp./B. sp. & 81.34 & 0.01 & 0.01 & 0.01 & 0.00 & 0.00 \\
\hline
\end{tabular}

way, low temperatures with respect to optimum have been related to the proliferation of amplicons with mismatches $[39,40]$. On the other hand, it has been shown that high annealing temperatures with respect to optimum tend to increase the ratio of amplification of one-mismatch to nomismatch sequences [41, 42]. Regardless of the diversity of opinions, knowledge of the factors that intervene in the differences of relative abundance of OTUs at different annealing temperatures is still incomplete; hence, primer mismatches may not be the only cause driving these changes [37].

3.5. CA and PCoA. CA a) and b) are shown in Figure S2. When the similarity of all OTUs identified was compared, there were no relevant differences between results generated by PCR at the different annealing temperatures assayed (CA a)). However, CA b), which analyzes only OTUs with $>1 \%$ relative abundance, clearly shows significant differences between the results generated at $44^{\circ} \mathrm{C}$ compared to the rest of annealing temperatures tested. This is in accordance with the heat maps generated for the bioreactors sampled (Figure 1). This implies that Bray-Curtis dissimilarities between annealing temperatures are less pronounced when samples are studied to their full sampling depths.

Phylogeny-dependent CA c) for each bioreactor is shown in Figure S3. Similarity between samples varies depending on the bioreactor analyzed. Samples from lab-scale bioreactors showed a higher phylogeny-based similarity for 


\begin{tabular}{|c|c|c|c|c|c|c|}
\hline \multirow{2}{*}{\multicolumn{7}{|c|}{\begin{tabular}{|r|} 
A \\
Acidobacterium sp.
\end{tabular}}} \\
\hline & & & & & & \\
\hline \multicolumn{7}{|l|}{ Anaeromyxobacter sp. } \\
\hline \multicolumn{7}{|l|}{ Bacillus sp. } \\
\hline \multicolumn{7}{|l|}{ Bacteroides sp. } \\
\hline \multicolumn{7}{|l|}{ Bdellovibrio bacteriovorus } \\
\hline \multirow{2}{*}{\multicolumn{7}{|c|}{ Bellilinea sp. }} \\
\hline \multicolumn{4}{|l|}{ Brocadia sp. } & & & \\
\hline \multirow{2}{*}{\multicolumn{7}{|c|}{ Brumimicrobium sp. }} \\
\hline \multirow{2}{*}{\multicolumn{6}{|c|}{ Carboxydibrachium sp. }} & \\
\hline \multicolumn{3}{|l|}{ Chitinophaga sp. } & & & & \\
\hline \multirow{2}{*}{\multicolumn{7}{|c|}{$\begin{array}{l}\text { Chloroflexus sp. } \\
\text { Clostridium sp. }\end{array}$}} \\
\hline & & & & & & \\
\hline \multirow{2}{*}{\multicolumn{7}{|c|}{\begin{tabular}{|l} 
Cytophaga sp. \\
Denitratisoma sp.
\end{tabular}}} \\
\hline & & & & & & \\
\hline \multirow{2}{*}{\multicolumn{4}{|c|}{ Derxia sp. }} & & & \\
\hline \multicolumn{5}{|l|}{ Fervidobacterium sp. } & & \\
\hline \multicolumn{7}{|l|}{ Fibrobacter sp. } \\
\hline \multirow{2}{*}{\multicolumn{7}{|c|}{ Flavobacterium sp. }} \\
\hline \multicolumn{6}{|l|}{ Fluviicola sp. } & \\
\hline \multicolumn{7}{|l|}{ Ignavibacterium album } \\
\hline \multirow{2}{*}{\multicolumn{7}{|c|}{ Longilinea sp. }} \\
\hline \multicolumn{2}{|l|}{ Microbulbifer sp. } & & & & & \\
\hline \multicolumn{7}{|l|}{ Nitrosococcus sp. } \\
\hline \multicolumn{7}{|l|}{ Nitrosomonas sp. } \\
\hline \multicolumn{7}{|l|}{ Nitrosospira sp. } \\
\hline \multicolumn{7}{|l|}{ Pedomicrobium sp. } \\
\hline \multicolumn{7}{|l|}{ Pelotomaculum terephthalicicum } \\
\hline \multicolumn{7}{|l|}{ Phycisphaera mikrensis } \\
\hline \multicolumn{7}{|l|}{ Prochlorococcus sp. } \\
\hline Rubrivivax sp. & & & & & & \\
\hline Sphingobacterium sp. & & & & & & \\
\hline Syntrophorhabdus aromaticivorans & & & & & & \\
\hline Verrucomicrobiur & & & & & & \\
\hline
\end{tabular}

\begin{tabular}{|c|c|}
\hline $0 \%$ & \\
\hline $0.10 \%$ & \\
\hline $1 \%$ & \\
\hline $2.50 \%$ & \\
\hline $5 \%$ & \\
\hline $7.50 \%$ & \\
\hline $10 \%$ & \\
\hline $15 \%$ & \\
\hline $20 \%$ & \\
\hline
\end{tabular}

\begin{tabular}{|c|c|c|c|c|c|c|}
\hline \multirow{2}{*}{\multicolumn{7}{|c|}{\begin{tabular}{|c|}
$\mathrm{N}$ \\
Acidobacterium $\mathrm{sp}$.
\end{tabular}}} \\
\hline & & & & & & \\
\hline \multirow{2}{*}{\multicolumn{7}{|c|}{$\begin{array}{l}\text { Anaerophaga sp. } \\
\text { Bacteroides sp }\end{array}$}} \\
\hline & & & & & & \\
\hline \multicolumn{7}{|c|}{ Brocadia anammoxidans } \\
\hline \multicolumn{7}{|l|}{ Carboxydibrachium sp. } \\
\hline \multicolumn{7}{|l|}{ Chloroflexus sp. } \\
\hline \multicolumn{7}{|l|}{ Clostridium sp. } \\
\hline \multirow{2}{*}{\multicolumn{7}{|c|}{$\frac{\text { Cytophaga sp. }}{\text { Derxiasp. }}$}} \\
\hline & & & & & & \\
\hline \multicolumn{2}{|l|}{ Endoriftia persephone } & & & & & \\
\hline \multicolumn{7}{|l|}{ Fibrobacter sp. } \\
\hline \multicolumn{7}{|l|}{ Flavobacterium sp. } \\
\hline \multicolumn{7}{|l|}{ Ignavibacterium album } \\
\hline \multicolumn{7}{|l|}{ Jettenia asiatica } \\
\hline \multicolumn{7}{|l|}{ Lewinella nigricans } \\
\hline \multicolumn{7}{|l|}{ Lewinella sp. } \\
\hline \multicolumn{7}{|l|}{ Magnetospirillum sp. } \\
\hline \multicolumn{7}{|l|}{ Nitrosomonas europaea } \\
\hline \multicolumn{7}{|l|}{ Nitrosomonas sp. } \\
\hline \multicolumn{7}{|l|}{ Novosphingobium $\mathrm{sp}$. } \\
\hline \multicolumn{7}{|l|}{ Pelobacter sp. } \\
\hline \multicolumn{7}{|c|}{ Pelotomaculum terephthalicicum } \\
\hline \multicolumn{7}{|c|}{ Phycisphaera mikrensis } \\
\hline \multicolumn{7}{|c|}{ Planctomyces sp. } \\
\hline \multicolumn{7}{|l|}{ Pseudoalteromonas sp. } \\
\hline \multicolumn{7}{|l|}{ Rhodanobacter sp. } \\
\hline \multicolumn{7}{|l|}{ Rikenella microfusus } \\
\hline Rubrivivax sp. & & & & & & \\
\hline Sphingobacterium sp. & & & & & & \\
\hline Syntrophomonas sp. & & & & & & \\
\hline Syntrophus sp. & & & & & & \\
\hline Terrimonas lutea & & & & & & \\
\hline Thiobacillus aquaesuli & & & & & & \\
\hline Thiobacillus sp. & & & & & & \\
\hline Thiobacillus sp. & & & & & & \\
\hline Thiobacillus sp. & & & & & & \\
\hline Verrucomicrobium sp. & & & & & & \\
\hline
\end{tabular}

\begin{tabular}{|c|c|}
\hline $0 \%$ & \\
\hline $0.10 \%$ & \\
\hline $1 \%$ & \\
\hline $2.50 \%$ & \\
\hline $5 \%$ & \\
\hline $7.50 \%$ & \\
\hline $10 \%$ & \\
\hline $15 \%$ & \\
\hline $20 \%$ & \\
\hline
\end{tabular}

Figure 2: Continued. 


\begin{tabular}{|c|c|c|c|c|c|c|c|}
\hline \multirow{3}{*}{\begin{tabular}{|l}
\multicolumn{1}{c}{$\mathrm{R}$} \\
Acidobacterium sp. \\
Alcanivorax $\mathrm{sp}$.
\end{tabular}} & $44^{\circ} \mathrm{C}$ & $45^{\circ} \mathrm{C}$ & $46^{\circ} \mathrm{C}$ & $47^{\circ} \mathrm{C}$ & $48^{\circ} \mathrm{C}$ & $49^{\circ} \mathrm{C}$ & \\
\hline & & & & & & & \\
\hline & & & & & & & \\
\hline Bacillus sp. & & & & & & & \\
\hline Bergeyella sp. & & & & & & & \\
\hline Brocadia fulgida & & & & & & & \\
\hline Brocadia sp. & & & & & & & \\
\hline Carboxydibrachium sp. & & & & & & & \\
\hline Chloroflexus sp. & & & & & & & \\
\hline Clostridium sp. & & & & & & & $0 \%$ \\
\hline Comamonas sp. & & & & & & & $0.10 \%$ \\
\hline Cytophaga sp. & & & & & & & \\
\hline Denitratisoma sp. & & & & & & & $1 \%$ \\
\hline Derxia sp. & & & & & & & $2.50 \%$ \\
\hline \begin{tabular}{|l} 
Dokdonella sp. \\
\end{tabular} & & & & & & & \\
\hline Flavobacterium sp. & & & & & & & $5 \%$ \\
\hline Ignavibacterium album & & & & & & & \\
\hline Kaistella sp. & & & & & & & $7.50 \%$ \\
\hline Mariprofundus ferrooxydans & & & & & & & $10 \%$ \\
\hline Nitrosococcus sp. & & & & & & & \\
\hline Nitrosomonas sp. & & & & & & & $15 \%$ \\
\hline \begin{tabular}{|l} 
Nitrosospira sp. \\
\end{tabular} & & & & & & & $20 \%$ \\
\hline Phycisphaera mikrensis & & & & & & & $20 \%$ \\
\hline Prochlorococcus sp. & & & & & & & \\
\hline \begin{tabular}{|l|} 
Riemerella sp. \\
\end{tabular} & & & & & & & \\
\hline Sphingobacterium sp. & & & & & & & \\
\hline Syntrophus sp. & & & & & & & \\
\hline Terrimonas lutea & & & & & & & \\
\hline Verrucomicrobium sp. & & & & & & & \\
\hline
\end{tabular}

Figure 2: Heat maps of OTUs > 1\% relative abundance in full scale bioreactors Appeldorn (A), Olburgen (N), and Rotterdam (R).

all the annealing temperatures tested. No significant differences at $80 \%$ similarity were found in bioreactor Low Temperature CANON, and three clusters were formed at 90\% similarity. For bioreactor Lab MBR there were no significant differences at $70 \%$ similarity, but three clusters were generated at $80 \%$ and $90 \%$ similarity. Full-scale bioreactors showed lower phylogeny-based similarity, with significant differences at $70 \%$ for bioreactors $\mathrm{N}$ and $\mathrm{R}$ and sequences grouped in five or six clusters at $90 \%$ similarity in all cases. This leads to the assumption that differences in bacterial communities obtained at different annealing temperatures are more pronounced in more complex ecosystems.

Phylogeny-dependent PCoA 2D views are offered in Figure S4. PCoA was done to double check the results obtained by CA of samples. Phylogeny-dependent PCoA showed that $44^{\circ} \mathrm{C}$ tended to discriminate from the other annealing temperatures in terms of microbial community structure explanation. On the other hand, samples annealed at $45^{\circ} \mathrm{C}$ and $48^{\circ} \mathrm{C}$ seemed to be related in terms of microbial community structure. As also proven by cluster analysis, the differences between various annealing temperatures were found more pronounced as the complexity of the bacterial communities increased.

Some authors have reported that differences in annealing temperature do not significantly affect the microbial community structure of chicken caecal samples [37]. In our case, differences in microbial community structure at both full sampling depth and at $>1 \%$ OTUs were confirmed.
3.6. Species Richness and Hill Diversity Indices. Values for individuals computed and original, interpolated and extrapolated species richness are summarized in Table 3. Rating for performance of the different annealing temperatures based on species richness is shown in Table 4. Differences in species richness are accounted at the original sequencing depth, interpolated to the lowest number of reads per bioreactor, and extrapolated to the highest number of reads per bioreactor. Even though species richness comparison cannot be performed at different sequencing depths, methods for interpolation and extrapolation of rarefaction curves can precisely estimate species richness diversity of samples with different number of reads, making comparison between them possible [29].

Differences in species richness and number of reads obtained at each annealing temperature can be appreciated. As a main trend, $44^{\circ} \mathrm{C}$ is the temperature that offered the highest number of reads, followed by $45^{\circ} \mathrm{C}$ and $46^{\circ} \mathrm{C}$. It has been suggested that annealing temperatures lower than the optimum increase the number of PCR products generated [43]. The lowest number of reads was obtained at $49^{\circ} \mathrm{C}$. $48^{\circ} \mathrm{C}$ was the temperature generating a higher interpolated species richness, while at $44^{\circ} \mathrm{C}$ a poorer performance was observed, and $44^{\circ} \mathrm{C}$ was also the worst among all annealing temperatures regarding original species richness. Extrapolated species richness of samples was higher at $45^{\circ} \mathrm{C}$, followed by $48^{\circ} \mathrm{C}$.

In conclusion, $45^{\circ} \mathrm{C}$ is the annealing temperature showing the best performance regarding the expression of species 
TABLE 3: Values for individuals computed, original species richness $S$ (est), interpolated species richness $S$ (int), and extrapolated species richness $S($ ext).

\begin{tabular}{|c|c|c|c|c|c|}
\hline & Temperature & Individuals (computed) & $S($ est) & $S$ (int) & $S($ ext $)$ \\
\hline \multirow{6}{*}{$\begin{array}{l}\text { Lab MBR } \\
\text { (T2) }\end{array}$} & $44^{\circ} \mathrm{C}$ & 11646 & 42 & 34.8 & 42.99 \\
\hline & $45^{\circ} \mathrm{C}$ & 16895 & 148 & 85.6 & 148.4 \\
\hline & $46^{\circ} \mathrm{C}$ & 17336 & 117 & 67 & 117 \\
\hline & $47^{\circ} \mathrm{C}$ & 3162 & 78 & 76.8 & 85.67 \\
\hline & $48^{\circ} \mathrm{C}$ & 5883 & 100 & 79.2 & 108.9 \\
\hline & $49^{\circ} \mathrm{C}$ & 3024 & 105 & 105 & 117.3 \\
\hline \multirow{6}{*}{$\begin{array}{l}\text { Low Temperature } \\
\text { CANON } \\
\text { (TC) }\end{array}$} & $44^{\circ} \mathrm{C}$ & 11438 & 61 & 30.1 & 38.65 \\
\hline & $45^{\circ} \mathrm{C}$ & 14362 & 179 & 100.3 & 179 \\
\hline & $46^{\circ} \mathrm{C}$ & 9545 & 155 & 94.4 & 163.1 \\
\hline & $47^{\circ} \mathrm{C}$ & 4145 & 119 & 99.5 & 131.6 \\
\hline & $48^{\circ} \mathrm{C}$ & 5068 & 133 & 99.3 & 147.9 \\
\hline & $49^{\circ} \mathrm{C}$ & 2394 & 87 & 87 & 95.53 \\
\hline \multirow{6}{*}{$\begin{array}{l}\text { Apeldoorn DEMON } \\
\text { (A) }\end{array}$} & $44^{\circ} \mathrm{C}$ & 9226 & 78 & 29.3 & 78.76 \\
\hline & $45^{\circ} \mathrm{C}$ & 9924 & 161.7 & 45.1 & 161.7 \\
\hline & $46^{\circ} \mathrm{C}$ & 654 & 73 & 55.6 & 79.11 \\
\hline & $47^{\circ} \mathrm{C}$ & 2192 & 141 & 66.5 & 156.9 \\
\hline & $48^{\circ} \mathrm{C}$ & 8206 & 258 & 68 & 265.2 \\
\hline & $49^{\circ} \mathrm{C}$ & 321 & 60 & 59.9 & 68.55 \\
\hline \multirow{6}{*}{$\begin{array}{l}\text { Olburgen CANON } \\
\text { (N) }\end{array}$} & $44^{\circ} \mathrm{C}$ & 17193 & 87 & 41.9 & 87 \\
\hline & $45^{\circ} \mathrm{C}$ & 2893 & 198 & 134.2 & 218.3 \\
\hline & $46^{\circ} \mathrm{C}$ & 947 & 141 & 140.9 & 160.7 \\
\hline & $47^{\circ} \mathrm{C}$ & 3180 & 205 & 135.7 & 221.9 \\
\hline & $48^{\circ} \mathrm{C}$ & 2462 & 197 & 139.2 & 217.1 \\
\hline & $49^{\circ} \mathrm{C}$ & 1905 & 174 & 133.8 & 192.6 \\
\hline \multirow{6}{*}{$\begin{array}{l}\text { Rotterdam 2-stage } \\
\text { anammox } \\
\text { (R) }\end{array}$} & $44^{\circ} \mathrm{C}$ & 12977 & 81 & 43.2 & 81 \\
\hline & $45^{\circ} \mathrm{C}$ & 5183 & 211 & 147.3 & 228 \\
\hline & $46^{\circ} \mathrm{C}$ & 3879 & 188 & 143.5 & 205.2 \\
\hline & $47^{\circ} \mathrm{C}$ & 4120 & 198 & 151.6 & 212.3 \\
\hline & $48^{\circ} \mathrm{C}$ & 1679 & 143 & 143 & 159.6 \\
\hline & $49^{\circ} \mathrm{C}$ & 1791 & 145 & 142.3 & 159.7 \\
\hline
\end{tabular}

TABLE 4: Ratings for the comparison of species richness for samples from different bioreactors at each annealing temperature. Higher mean ratio is related to higher performance of the annealing temperature.

\begin{tabular}{lccc}
\hline Temperature & Mean ratio individuals & Mean ratio S(int) & Mean ratio $S($ ext) \\
\hline $44^{\circ} \mathrm{C}$ & $89.36 \%$ & $32.89 \%$ & $31.00 \%$ \\
$45^{\circ} \mathrm{C}$ & $72.36 \%$ & $88.05 \%$ & $91.86 \%$ \\
$46^{\circ} \mathrm{C}$ & $41.79 \%$ & $86.87 \%$ & $72.43 \%$ \\
$47^{\circ} \mathrm{C}$ & $24.22 \%$ & $93.29 \%$ & $76.70 \%$ \\
$48^{\circ} \mathrm{C}$ & $37.09 \%$ & $93.51 \%$ & $84.76 \%$ \\
$49^{\circ} \mathrm{C}$ & $12.49 \%$ & $92.73 \%$ & $63.01 \%$ \\
\hline
\end{tabular}

richness of bacterial communities in the bioreactors studied, while annealing at $49^{\circ} \mathrm{C}$ offers a worse performance taking into account the low number of reads consistently obtained.

Hill diversity indices of first order (Shannon index) and second order (Simpson index) have been defended as the most robust method for comparison of bacterial assemblages from natural ecosystems [31]. Hill diversities of first order and second order for each sample are shown in Table 5. Ratings for the comparison of each annealing temperature based on the indices can be seen in Table 6 . Both indices showed the same quality pattern, with $45^{\circ} \mathrm{C}$ being the highest value followed closely by $49^{\circ} \mathrm{C}$ and $48^{\circ} \mathrm{C}$. Once again, $45^{\circ} \mathrm{C}$ 
TABLE 5: Values for the Shannon index and the Simpson index of all samples analyzed in the study.

\begin{tabular}{|c|c|c|c|}
\hline & Temperature & Shannon index & Simpson index \\
\hline \multirow{6}{*}{$\begin{array}{l}\text { Lab MBR } \\
\text { (T2) }\end{array}$} & $44^{\circ} \mathrm{C}$ & 1.559179 & 0.4866806 \\
\hline & $45^{\circ} \mathrm{C}$ & 1.657458 & 0.5265754 \\
\hline & $46^{\circ} \mathrm{C}$ & 0.9898754 & 0.2964455 \\
\hline & $47^{\circ} \mathrm{C}$ & 1.398619 & 0.4398892 \\
\hline & $48^{\circ} \mathrm{C}$ & 1.536843 & 0.480206 \\
\hline & $49^{\circ} \mathrm{C}$ & 1.665004 & 0.4945622 \\
\hline \multirow{6}{*}{$\begin{array}{l}\text { Low Temperature } \\
\text { CANON } \\
\text { (TC) }\end{array}$} & $44^{\circ} \mathrm{C}$ & 2.02004 & 0.7847361 \\
\hline & $45^{\circ} \mathrm{C}$ & 3.018484 & 0.9061173 \\
\hline & $46^{\circ} \mathrm{C}$ & 2.85764 & 0.8814217 \\
\hline & $47^{\circ} \mathrm{C}$ & 2.86951 & 0.8790168 \\
\hline & $48^{\circ} \mathrm{C}$ & 2.860865 & 0.8741682 \\
\hline & $49^{\circ} \mathrm{C}$ & 2.871034 & 0.8860556 \\
\hline \multirow{6}{*}{$\begin{array}{l}\text { Apeldoorn DEMON } \\
\text { (A) }\end{array}$} & $44^{\circ} \mathrm{C}$ & 2.297351 & 0.6694541 \\
\hline & $45^{\circ} \mathrm{C}$ & 3.561685 & 0.9399574 \\
\hline & $46^{\circ} \mathrm{C}$ & 3.286833 & 0.928345 \\
\hline & $47^{\circ} \mathrm{C}$ & 3.51128 & 0.9295173 \\
\hline & $48^{\circ} \mathrm{C}$ & 3.651016 & 0.944623 \\
\hline & $49^{\circ} \mathrm{C}$ & 3.366082 & 0.9407517 \\
\hline \multirow{6}{*}{$\begin{array}{l}\text { Olburgen CANON } \\
\text { (N) }\end{array}$} & $44^{\circ} \mathrm{C}$ & 2.959167 & 0.8714149 \\
\hline & $45^{\circ} \mathrm{C}$ & 3.979032 & 0.9632393 \\
\hline & $46^{\circ} \mathrm{C}$ & 4.039 & 0.9667856 \\
\hline & $47^{\circ} \mathrm{C}$ & 4.021377 & 0.9636953 \\
\hline & $48^{\circ} \mathrm{C}$ & 4.015465 & 0.9615441 \\
\hline & $49^{\circ} \mathrm{C}$ & 3.965338 & 0.9629424 \\
\hline \multirow{6}{*}{$\begin{array}{l}\text { Rotterdam 2-stage } \\
\text { anammox } \\
\text { (R) }\end{array}$} & $44^{\circ} \mathrm{C}$ & 2.497644 & 0.8499261 \\
\hline & $45^{\circ} \mathrm{C}$ & 3.910746 & 0.9644197 \\
\hline & $46^{\circ} \mathrm{C}$ & 3.87392 & 0.9619344 \\
\hline & $47^{\circ} \mathrm{C}$ & 3.903737 & 0.9636846 \\
\hline & $48^{\circ} \mathrm{C}$ & 3.865236 & 0.9630658 \\
\hline & $49^{\circ} \mathrm{C}$ & 3.902146 & 0.9643079 \\
\hline
\end{tabular}

TABLE 6: Rating for the comparison of species diversity for samples from different bioreactors at each annealing temperature. Higher mean ratio is related to higher performance of the annealing temperature.

\begin{tabular}{lcc}
\hline Temperature & Mean ratio Shannon index & Mean ratio Simpson index \\
\hline $44^{\circ} \mathrm{C}$ & $72.12 \%$ & $85.63 \%$ \\
$45^{\circ} \mathrm{C}$ & $99.12 \%$ & $99.83 \%$ \\
$46^{\circ} \mathrm{C}$ & $88.64 \%$ & $90.32 \%$ \\
$47^{\circ} \mathrm{C}$ & $94.92 \%$ & $95.71 \%$ \\
$48^{\circ} \mathrm{C}$ & $97.07 \%$ & $97.40 \%$ \\
$49^{\circ} \mathrm{C}$ & $97.14 \%$ & $98.24 \%$ \\
\hline
\end{tabular}

was the best annealing temperature for capturing diversity of bacterial communities inside the bioreactors analyzed.

No significant differences in species richness and evenness of chicken caecal samples studied through RT-PCR have been reported [37]. Nevertheless, other authors have shown that differences in annealing temperature lead to different bonding of primer and targeted region of genetic templates, having an impact over ecological parameters of environmental samples. This is caused by enhanced amplification of certain strains, which deviates relative abundance of these species, or by nonspecific bonding, which increases the microbial diversity recorded on the samples $[39,44]$. In our case, small differences in annealing temperature changed species richness, effective number of counts, and Hill 
diversities within the samples. Samples processed at $44^{\circ} \mathrm{C}$ accounted for the highest number of reads but surprisingly also contained the lowest species richness and diversity. This shows that annealing temperatures of $44^{\circ} \mathrm{C}$ reduced the estimation of the diversity of the system. Reduced diversity of samples analyzed at $44^{\circ} \mathrm{C}$ may rest on the fact that the primer is subjected to much more stringent bonding than that at the other annealing temperatures, therefore generating many sequences of a low number of species. All other annealing temperatures can capture the diversity of the ecosystem studied in a consistent fashion. $46^{\circ} \mathrm{C}$ offers a lower diversity quality values in comparison with the others.

In terms of species richness and diversity, $44^{\circ} \mathrm{C}$ offers poor results compared to the others, but it can be said that annealing temperatures ranging from 45 to $49^{\circ} \mathrm{C}$ offer good results. Nevertheless, $45^{\circ} \mathrm{C}$ stands as the optimal annealing temperature of all those tested due to superior species richness and diversity indices values. Interestingly, it yields better results in species richness and diversity than the in silico calculated salt-adjusted optimum for the primer. As suggested by Hecker and Roux, 1996 [43], annealing temperatures above and down the optimum annealing temperature theoretically calculated for a given primer increase number of reads obtained and specificity of PCR products. In this case, annealing temperature at $45^{\circ} \mathrm{C}$ gives better results, in terms of species richness and diversity, than the optimum salt-adjusted annealing temperature for the primer utilized.

\section{Conclusions}

The superior coverage of primer $530 \mathrm{~F}$ with respect to other popular universal primers was indicated through in silico testing. The ability of primer $530 \mathrm{~F}$ to target the majority of known anammox phylotypes was also demonstrated by in silico testing. Therefore, primer $530 \mathrm{~F}$ stands as the best universal primer available for the metagenomic analysis of microbial communities where anammox bacteria are expected to develop important ecological functions.

The 30 pyrosequencing analysis showed that the annealing temperature produces a severe effect over the microbial community structure discerned through pyrosequencing. Strong bias in the identification of anammox species in particular at annealing temperature of $44^{\circ} \mathrm{C}$ was observed in all the pyrosequencing samples for each of the five autotrophic nitrogen removal technologies. The six different annealing temperatures analyzed in the study showed different microbial community structure compositions as proved by phylogeny-based and non-phylogeny-based CA and PCoA. Differences among annealing temperatures could also be observed with respect to the number of individuals sequenced and species richness with $45^{\circ} \mathrm{C}$ being the best in these terms. In this sense, annealing temperatures of $45^{\circ} \mathrm{C}$ demonstrate good coverage of total bacteria and anammox species, high number of reads, the highest species richness, and the highest diversity indices values. Therefore, results show that autotrophic nitrogen removal bioreactor bacterial community analyses including anammox bacteria can be done using the universal primer 530F with annealing temperature of $45^{\circ} \mathrm{C}$. Under these conditions, this procedure is a good approach for the bacterial diversity study in autotrophic nitrogen removal technologies using pyrosequencing methods.

\section{Conflict of Interests}

The authors declare that there is no conflict of interests regarding the publication of this paper.

\section{Authors' Contribution}

Alejandro Gonzalez-Martinez was responsible for the bioreactors field study and in silico testing of the different primers. Alejandro Gonzalez-Martinez was mainly responsible for molecular biology experimental procedures, and Ben A. Abbas was also responsible for this. Alejandro RodriguezSanchez was mainly responsible for the statistical analysis of samples and microbial ecology analysis, while Maria Victoria Martinez-Toledo and Belén Rodelas also were responsible for microbial ecology analysis. Alejandro GonzalezMartinez, Alejandro Rodriguez-Sanchez, Belén Rodelas, and Jesus Gonzalez-Lopez were responsible for writing the paper. Alejandro Gonzalez-Martinez and Alejandro RodriguezSanchez were responsible for the conformation of all tables and figures. Alejandro Gonzalez-Martinez, Belén Rodelas, Maria Victoria Martinez-Toledo, Mark C. M. van Loosdrecht, F. Osorio, and Jesus Gonzalez-Lopez were responsible for revision of the paper.

\section{Acknowledgement}

The authors received a financial support from a collaborator company but it has not participated in the work development.

\section{References}

[1] M. Strous, J. A. Fuerst, E. H. M. Kramer et al., "Missing lithotroph identified as new planctomycete," Nature, vol. 400, no. 6743, pp. 446-449, 1999.

[2] T. Dalsgaard, B. Thamdrup, and D. E. Canfield, "Anaerobic ammonium oxidation (anammox) in the marine environment," Research in Microbiology, vol. 156, no. 4, pp. 457-464, 2005.

[3] M. M. M. Kuypers, A. O. Silekers, G. Lavik et al., "Anaerobic ammonium oxidation by anammox bacteria in the Black Sea," Nature, vol. 422, no. 6932, pp. 608-611, 2003.

[4] B. Thamdrup, T. Dalsgaard, M. M. Jensen, O. Ulloa, L. Farías, and R. Escribano, "Anaerobic ammonium oxidation in the oxygen-deficient waters off Northern Chile," Limnology and Oceanography, vol. 51, no. 5, pp. 2145-2156, 2006.

[5] S. Ganesh, D. J. Parris, E. F. Delong, and F. J. Stewart, "Metagenomic analysis of size-fractionated picoplankton in a marine oxygen minimum zone," ISME Journal, vol. 8, no. 1, pp. 187-211, 2014.

[6] L.-D. Shen, S. Liu, L.-P. Lou et al., "Broad distribution of diverse anaerobic ammonium-oxidizing bacteria in Chinese agricultural soils," Applied and Environmental Microbiology, vol. 79, no. 19, pp. 6167-6172, 2013.

[7] S. M. Kotay, B. L. Mansell, M. Hogsett, H. Pei, and R. Goel, "Anaerobic ammonia oxidation (ANAMMOX) for side-stream treatment of anaerobic digester filtrate process performance and 
microbiology," Biotechnology and Bioengineering, vol. 110, no. 4, pp. 1180-1192, 2013.

[8] A. González-Martínez, J. M. Poyatos, E. Hontoria, J. GonzalezLopez, and F. Osorio, "Treatment of effluents polluted by nitrogen with new biological technologies based on autotrophic nitrification-denitrification processes," Recent Patents on Biotechnology, vol. 5, no. 2, pp. 74-84, 2011.

[9] M. S. M. Jetten, M. Wagner, J. Fuerst, M. C. M. van Loosdrecht, G. Kuenen, and M. Strous, "Microbiology and application of the anaerobic ammonium oxidation ('anammox') process," Current Opinion in Biotechnology, vol. 12, no. 3, pp. 283-288, 2001.

[10] S. Sri Shalini and K. Joseph, "Nitrogen management in landfill leachate: application of SHARON, ANAMMOX and combined SHARON-ANAMMOX process," Waste Management, vol. 32, no. 12, pp. 2385-2400, 2012.

[11] T. Liu, D. Li, H. Zeng et al., "Biodiversity and quantification of functional bacteria in completely autotrophic nitrogen-removal over nitrite (CANON) process," Bioresource Technology, vol. 118, pp. 399-406, 2012.

[12] Z.-X. Quan, S.-K. Rhee, J.-E. Zuo et al., "Diversity of ammonium-oxidizing bacteria in a granular sludge anaerobic ammonium-oxidizing (anammox) reactor," Environmental Microbiology, vol. 10, no. 11, pp. 3130-3139, 2008.

[13] Z. Hu, D. R. Speth, K.-J. Francoijs, Z.-X. Quan, and M. S. M. Jetten, "Metagenome analysis of a complex community reveals the metabolic blueprint of anammox bacterium 'Candidatus Jettenia asiatica"' Frontiers in Microbiology, vol. 3, article 366, 2012.

[14] Q. Yang, Z. Jia, R. Liu, and J. Chen, "Molecular diversity and anammox activity of novel planctomycete-like bacteria in the wastewater treatment system of a full-scale alcohol manufacturing plant," Process Biochemistry, vol. 42, no. 2, pp. 180-187, 2007.

[15] X.-R. Li, B. Du, H.-X. Fu et al., "The bacterial diversity in an anaerobic ammonium-oxidizing (anammox) reactor community," Systematic and Applied Microbiology, vol. 32, no. 4, pp. 278-289, 2009.

[16] B.-J. Ni, B.-L. Hu, F. Fang et al., "Microbial and physicochemical characteristics of compact anaerobic ammonium-oxidizing granules in an upflow anaerobic sludge blanket reactor," Applied and Environmental Microbiology, vol. 76, no. 8, pp. 2652-2656, 2010.

[17] P. Han, Y.-T. Huang, J.-G. Lin, and J.-D. Gu, "A comparison of two 16S rRNA gene-based PCR primer sets in unraveling anammox bacteria from different environmental samples," Applied Microbiology and Biotechnology, vol. 97, no. 24, pp. 10521-10529, 2013.

[18] B. Xie, Z. Lv, C. Hu, X. Yang, and X. Li, "Nitrogen removal through different pathways in an aged refuse bioreactor treating mature landfill leachate," Applied Microbiology and Biotechnology, vol. 97, no. 20, pp. 9225-9234, 2013.

[19] M. S. M. Jetten, L. van Niftrik, M. Strous, B. Kartal, J. T. Keltjens, and H. J. M. Op Den Camp, "Biochemistry and molecular biology of anammox bacteria," Critical Reviews in Biochemistry and Molecular Biology, vol. 44, no. 2-3, pp. 65-84, 2009.

[20] P. Junier, V. Molina, C. Dorador et al., "Phylogenetic and functional marker genes to study ammonia-oxidizing microorganisms (AOM) in the environment," Applied Microbiology and Biotechnology, vol. 85, no. 3, pp. 425-440, 2010.

[21] S. E. Dowd, T. R. Callaway, R. D. Wolcott et al., "Evaluation of the bacterial diversity in the feces of cattle using $16 \mathrm{~S}$
rDNA bacterial tag-encoded FLX amplicon pyrosequencing (bTEFAP)," BMC Microbiology, vol. 8, article 125, 2008.

[22] W. Rychlik, W. J. Spencer, and R. E. Rhoads, "Optimization of the annealing temperature for DNA amplification in vitro," Nucleic Acids Research, vol. 18, no. 21, pp. 6409-6412, 1990.

[23] X. Chen, P. Liu, and H.-H. Chou, "Whole-genome thermodynamic analysis reduces siRNA off-target effects," PLoS ONE, vol. 8, no. 3, Article ID e58326, 2013.

[24] D. Dobrijevic, G. Di Liberto, K. Tanaka et al., "High-throughput system for the presentation of secreted and surface-exposed proteins from Gram-positive bacteria in functional metagenomic studies," PLoS ONE, vol. 8, no. 6, Article ID e65956, 2013.

[25] S. Nakano, Y. Morizane, N. Makisaka et al., "Development of a highly sensitive immuno-PCR assay for the measurement of $\alpha$ galactosidase A protein levels in serum and plasma," PLoS ONE, vol. 8, no. 11, Article ID e78588, 2013.

[26] R. C. Edgar, "Search and clustering orders of magnitude faster than BLAST," Bioinformatics, vol. 26, no. 19, pp. 2460-2461, 2010.

[27] R. C. Edgar, B. J. Haas, J. C. Clemente, C. Quince, and R. Knight, "UCHIME improves sensitivity and speed of chimera detection," Bioinformatics, vol. 27, no. 16, pp. 2194-2200, 2011.

[28] D. E. Wood and S. L. Salzberg, "Kraken: ultrafast metagenomic sequence classification using exact alignments," Genome Biology, vol. 15, no. 3, article R46, 2014.

[29] R. K. Colwell, A. Chao, N. J. Gotelli et al., "Models and estimators linking individual-based and sample-based rarefaction, extrapolation and comparison of assemblages," Journal of Plant Ecology, vol. 5, no. 1, pp. 3-21, 2012.

[30] R Development Core Team, R: A Language and Environment for Statistical Computing, R Foundation for Statistical Computing, Vienna, Austria, 2008, http://www.R-project.org.

[31] B. Haegeman, J. Hamelin, J. Moriarty, P. Neal, J. Dushoff, and J. S. Weitz, "Robust estimation of microbial diversity in theory and in practice," The ISME Journal, vol. 7, no. 6, pp. 1092-1101, 2013.

[32] K. Malhotra, L. Foltz, W. C. Mahoney, and P. A. Schueler, "Interaction and effect of annealing temperature on primers used in differential display RT-PCR," Nucleic Acids Research, vol. 26, no. 3, pp. 854-856, 1998.

[33] D. Bru, F. Martin-Laurent, and L. Philippot, "Quantification of the detrimental effect of a single primer-template mismatch by real-time PCR using the 16 S rRNA gene as an example," Applied and Environmental Microbiology, vol. 74, no. 5, pp. 1660-1663, 2008.

[34] W. R. L. van der Star, A. I. Miclea, U. G. J. M. van Dongen, G. Muyzer, C. Picioreanu, and M. C. M. van Loosdrecht, "The membrane bioreactor: a novel tool to grow anammox bacteria as free cells," Biotechnology and Bioengineering, vol. 101, no. 2, pp. 286-294, 2008.

[35] T. Lotti, Monitoraggio del proceso anammox: aspetti fisiologici per unutilizzo in piena scala, Università degli Studi della Basilicata, Potenza, Italy, 2011.

[36] Z. Hu, T. Lotti, M. de Kreuk et al., "Nitrogen removal by a nitritation-anammox bioreactor at low temperature," Applied and Environmental Microbiology, vol. 79, no. 8, pp. 2807-2812, 2013.

[37] M. J. Sergeant, C. Constantinidou, T. Cogan, C. W. Penn, and M. J. Pallen, "High-throughput sequencing of 16s rRNA gene amplicons: Effects of extraction procedure, primer length and annealing temperature," PLOS ONE, vol. 7, no. 5, Article ID e38094, 2012. 
[38] S. Wang and R. E. Levin, "Thermal factors influencing detection of Vibrio vulnificus using real-time PCR," Journal of Microbiological Methods, vol. 69, no. 2, pp. 358-363, 2007.

[39] J. T. Hsu, S. Das, and S. Mohapatra, "Polymerase chain reaction engineering," Biotechnology and Bioengineering, vol. 55, no. 2, pp. 359-366, 1997.

[40] M. J. Claesson, Q. Wang, O. O'Sullivan et al., "Comparison of two next-generation sequencing technologies for resolving highly complex microbiota composition using tandem variable 16 S rRNA gene regions," Nucleic Acids Research, vol. 38, article e200, 2010.

[41] K. Ishii and M. Fukui, "Optimization of annealing temperature to reduce bias caused by a primer mismatch in multitemplate PCR," Applied and Environmental Microbiology, vol. 67, no. 8, pp. 3753-3755, 2001.

[42] R. Sipos, A. J. Székely, M. Palatinszky, S. Révész, K. Márialigeti, and M. Nikolausz, "Effect of primer mismatch, annealing temperature and PCR cycle number on 16S rRNA gene-targetting bacterial community analysis," FEMS Microbiology Ecology, vol. 60, no. 2, pp. 341-350, 2007.

[43] K. H. Hecker and K. H. Roux, "High and low annealing temperatures increase both specificity and yield in touchdown and stepdown PCR," BioTechniques, vol. 20, no. 3, pp. 478-485, 1996.

[44] K. Malhotra, L. Foltz, W. C. Mahoney, and P. A. Schueler, "Interaction and effect of annealing temperature on primers used in differential display RT-PCR," Nucleic Acids Research, vol. 26, no. 3, pp. 854-856, 1998. 

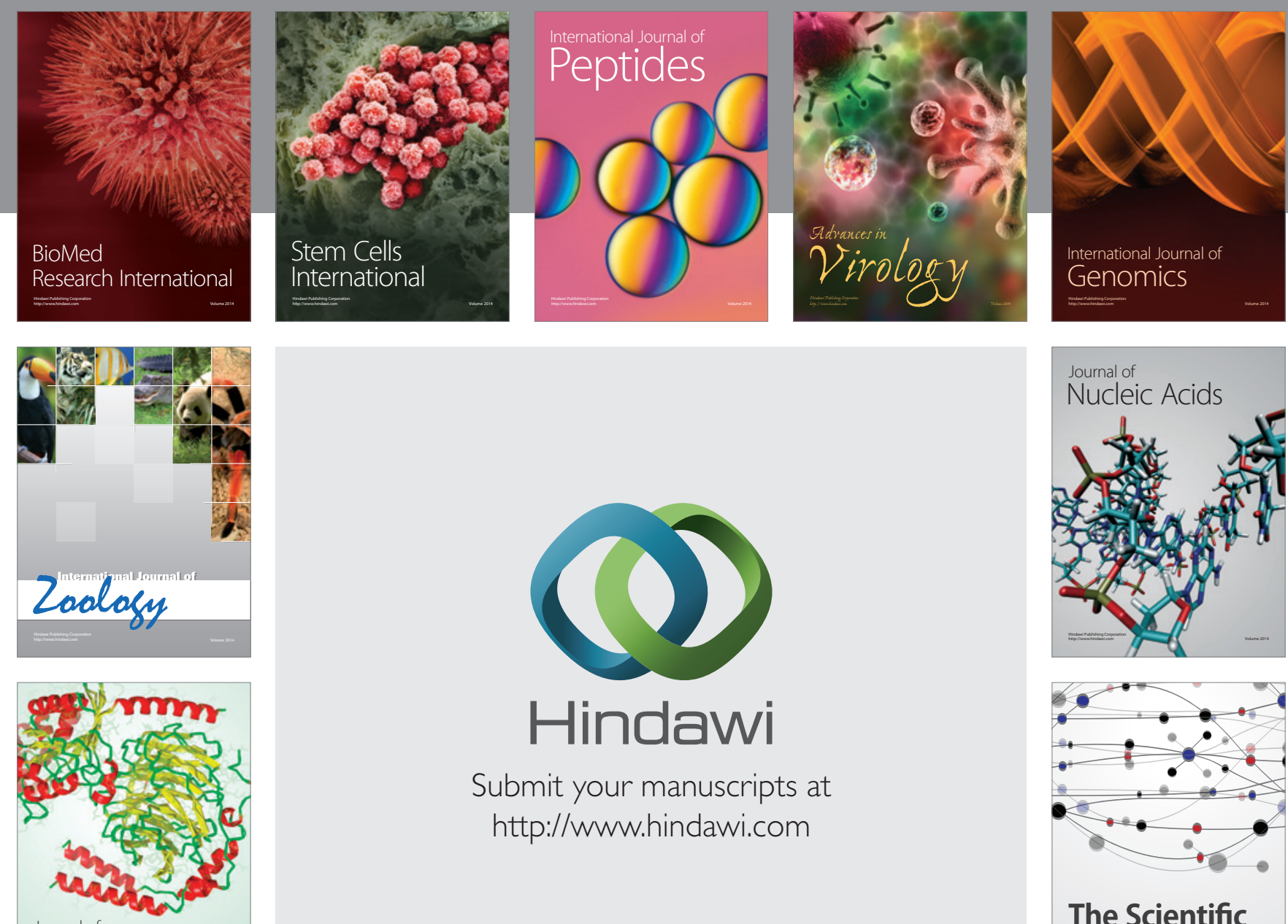

Submit your manuscripts at

http://www.hindawi.com

Journal of
Signal Transduction
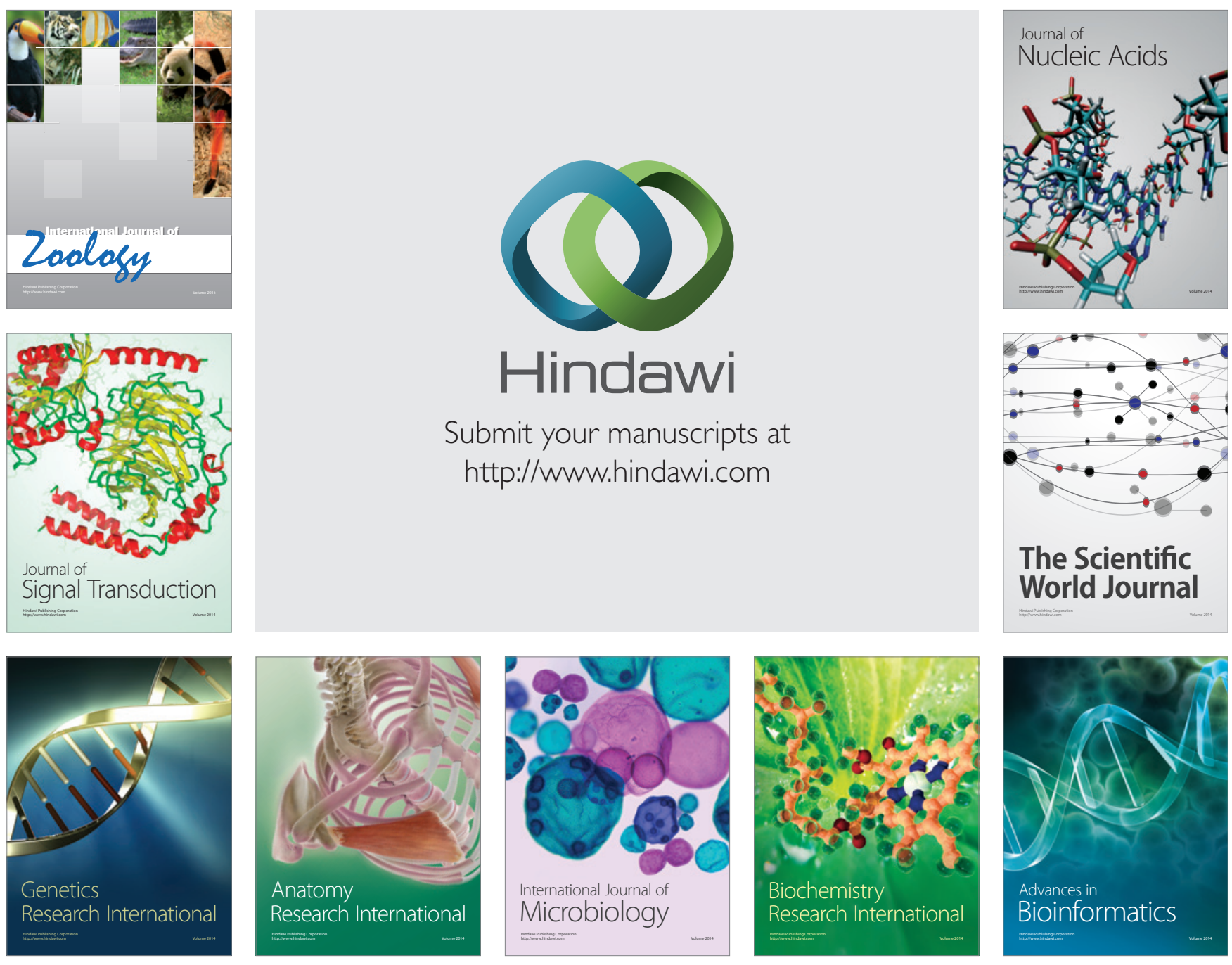

The Scientific World Journal
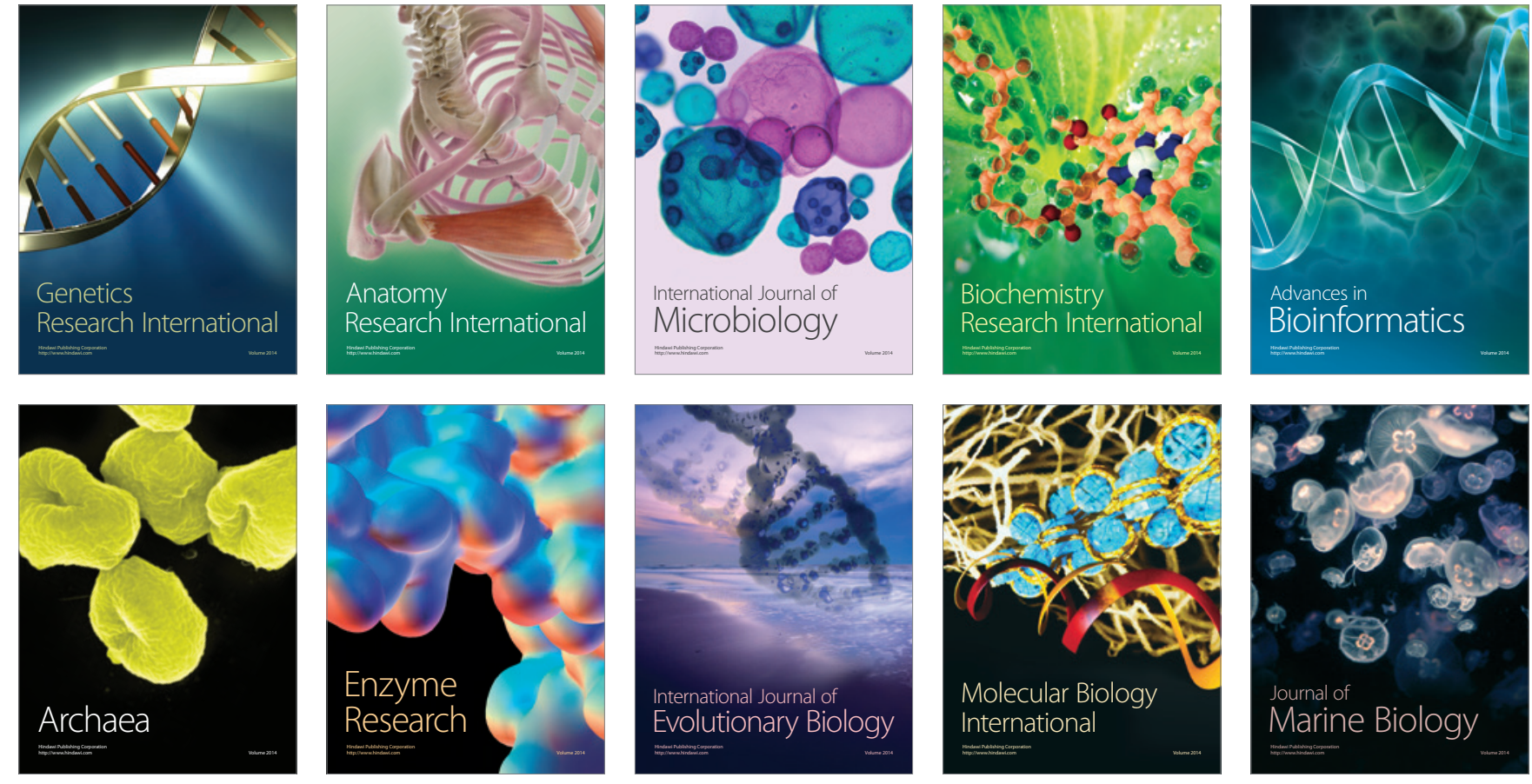